\title{
Sexual autonomy and violence against women in Nigeria: Assessing the impact of Covid-19 pandemic
}

\author{
Tolulope R Ibitoye \\ Lecturer, Department of Private and Property Law, Faculty of Law, University of \\ Ibadan, Ibadan, Nigeria
}

\section{Folakemi Ajagunna}

Lecturer, Department of Private and Property Law, Faculty of Law, University of Ibadan, Ibadan, Nigeria

\begin{abstract}
SUMMARY
Sexual and reproductive rights are centred on an individual's autonomy. However, these rights are jeopardised when women and girls are faced with sexual violence. Recently, there was reported increase in violence against women and girls, constituting an infringement of their human rights. Relieving this burden has become a human rights commitment for most countries including Nigeria. Therefore, this article examines how these rights were impacted during the COVID-19 pandemic in Nigeria. It examines reports from media sources, and conducted in-depth interviews with Forty-five (45) women in a bid to elicit their responses on their experiences during the pandemic. The research found that the pandemic had both positive and negative impacts on the women's sexual autonomy. This article recommends the creation of more awareness for women, the fostering of political will, and dedicated funding to ensure active implementation and better protection of women's rights in Nigeria.
\end{abstract}

\section{Introduction}

The realisation of an individual's Sexual and Reproductive Health Rights (SRHR) is indispensable in attaining the right to the highest standard of physical and mental health. This right is protected in various international human rights conventions. SRHR allows women to be in control of their own bodies and decide if, when, with whom and how often to bear children. SRHR depends on timely, comprehensive sexuality education that allows individuals to learn about their bodies, to understand relationships, to make informed decisions about their sexuality, and to stand up against sexual harassment, exploitation and abuse. Consequently, it is important to note that SRHR includes the right to an effective remedy for violations of fundamental rights. ${ }^{1}$

1 WHO Defining Sexual Health' 2006 Updated 2009 http://www.who.int/ reproductivehealth/topics/sexual_health/sh_definitions/en/ (accessed 202008-03).

How to cite: Ibitoye \& Ajagunna 'Sexual autonomy and violence against women in Nigeria: Assessing the impact of Covid-19 pandemic' 2021 De Jure Law Journal 141 - 159 http://dx.doi.org/10.17159/2225-7160/2021/v54a9 
In some countries, including Nigeria, women and girls are forced to marry and have sex with men they do not desire. Women are unable to depend on the government to protect them from physical violence in the home. Women in state custody face sexual assault by their jailers. Women are punished for having sex outside of marriage or with a person of their choice. Husbands and other male family members obstruct or dictate women's access to reproductive health care. This is mainly because the culture has always been a male-centric one; with women and girls been treated as objects of sexual pleasure and not as individuals who can have their own sexual desires and fantasies. ${ }^{2}$

Reproductive rights are human rights, and the ability to fully exercise them, is key to sustainable development. When these rights are in jeopardy, they negatively and conversely affect the rights to health and consequently the achievement of Sustainable Development Goals (SDG). It is increasingly being realised that SRHR constitute an integral core of the SDG. Nations of the world committed themselves to ensure that these goals are realised by the year 2030. This was also done by breaking down these goals into achievable milestone and targets. For instance, SDG 3 aims at good health and well-being. ${ }^{3}$ This goal is further broken down to 8 targets which, among others, aims at ensuring universal access to sexual and reproductive health-care services, including family planning, information and education, and the integration of reproductive health into national strategies and programs by the year $2030 .{ }^{4}$ Nigeria, being a member nation in the UN was not left out in the implementation of programs and policies to realise this goal amidst other SDG goals. However, the onset of the COVID-19 pandemic has had an impact on the implementation of these goals. The aim of this article is to examine how the COVID-19 pandemic has impacted on sexual autonomy which is a core component of sexual and reproductive rights in Nigeria. In achieving this aim, the article examines the concept of sexual autonomy and sexual violence. It sets out the legal provisions which guarantee this right in the Nigerian legal system. The article further expounds on the COVID-19 pandemic in Nigeria and how this has affected sexual autonomy and violence against women. The article concludes with suggestion on how the reproductive rights of women can be improved upon with a view to the SDG timelines and bearing in mind that the pandemic may be with us for longer than anticipated.

2 Omo-Aghoja "Sexual and reproductive health: Concepts and current status among Nigerian" 2013 African Journal of Medical and Health Sciences 103-113.

3 United Nations Sustainable Development Goals Goal 3: Good Health and Well-Being https://www.undp.org/content/undp/en/home/sustainable-dev elopment-goals/goal-3-good-health-and-well-being.html (accessed 2021-0224).

4 WHO Sustainable Development Goals https://www.who.int/health-topics/ sustainable-development-goals\#tab = tab_2 (accessed 2021-02-24). 


\section{What is sexual autonomy?}

Sexual autonomy depicts a person's prerogative to determine when, with whom, and under what circumstances they engage in sexual activity; to only engage in sexual activity to which they consent. ${ }^{5}$ Put differently, sexual autonomy involves the right to choose to either have sex or to refuse. In Coker $v$ Georgia, ${ }^{6}$ the Supreme Court held it unconstitutional to sentence someone to death for the crime of rape, thus, the Court enunciated why rape is proscribed as it infringes on a person's "privilege of choosing those with whom intimate relationships are to be established," that is, their sexual autonomy. Closely related to the concept of sexual autonomy is sexual violence. It is "any sexual act, attempt to obtain a sexual act, unwanted sexual comments or advances, or acts to traffic, or otherwise directed, against a person's sexuality using coercion, by any person regardless of their relationship to the victim, in any setting, including but not limited to home and work." ${ }^{7}$ Furthermore, it may take various forms, such as, rape within marriage or dating relationships; rape by strangers; systematic rape during armed conflict; unwanted sexual advances or sexual harassment, including demanding sex in return for favours; sexual abuse of mentally or physically disabled people; sexual abuse of children; forced marriage or cohabitation, including the marriage of children; denial of the right to use contraception or to adopt other measures to protect against sexually transmitted diseases; forced abortion; violent acts against the sexual integrity of women, including female genital mutilation and obligatory inspections for virginity; and forced prostitution and trafficking of people for the purpose of sexual exploitation. ${ }^{8}$ Violence against women is an issue of public health and human rights concern in Nigeria. ${ }^{9}$ Physical violence is also associated with sexual abuse and loss of autonomy. These negative acts on women apart from leading to physical injury and death can also result in mental and emotional trauma for women.

\section{Reproductive health rights and sustainable development goals}

In the year 2015, nations of the world adopted the SDGs. Each of these goals has specific targets which are to be achieved in the next 15 years.

5 Brown "Against Sexual Autonomy: Why Sex Law's Lodestar Should Be SelfPossession" (2014-12-16) https://www.libertarianism.org/columns/againstsexual-autonomy-why-sex-laws-lodestar-should-be-self-possession\#: :text $=$ Put $\% 20$ broadly $\% 2$ C \% 20sexual \% 20autonomy \% 20means, activity \% 20to $\%$ 20which \% 20they \% 20consent (accessed 2020-08-03).

$6 \quad$ Coker v Georgia 433 U.S. 584 (1977).

7 WHO Violence against women - Intimate partner and sexual violence against women 2011 Geneva, World Health Organization 149.

8 WHO 149-150.

9 Atsenuwa and Ezeilo Review of the laws relating to reproductive health rights in Nigeria 2006 Law Reproductive Health and Human Rights Women Aids Collective 148. 
The SDGs include one broad health goal and over 50 health-related targets which are applicable to all countries, irrespective of their level of development. ${ }^{10}$ In the field of SRHR, the SDGs include several relevant goals and targets such as those related to health, education and gender equality. Goal 5, target 5.6 aims at ensuring universal access to SRH services, including family planning, information and education and integration of reproductive health into national strategies and programs. ${ }^{11}$ Apart from this, target 5.2 aims at eliminating all forms of violence against all women and girls in public and private spheres, including trafficking, sexual and other types of exploitation. ${ }^{12}$ The inclusion of these specific targets is a recognition that addressing all forms of violence and harmful practices against women and girls is central to achieving gender equality and women's empowerment, which is essential for sustainable development. ${ }^{13}$

It is gradually being recognised that when a woman's sexual autonomy is respected and there is freedom from sexual violence, it contributes to the realisation of SRHR. Improved SRHR likewise leads to better and improved health outcomes and translates to development of the society at large. Although recorded successes were documented in achieving Millennium Development Goals, not much progress was recorded in the area of SRHR because the MDGs were not specific in the roles of SRHR in improving health outcomes. In 2015, the Guttmacher Institute recommended indicators specifically for SRHR. The purpose of the indicators was to assess how countries have fared in relation to achieving the SDGs and targets. ${ }^{14}$ Amongst other indicators, is that which evaluates access to respect for women's autonomy within marriage. ${ }^{15}$ From data available from the World Health Organization, reproductive health conditions are responsible for 22 percent of health years of life lost by women annually. ${ }^{16}$ This is a grappling figure when compared with that of 3 percent attributable to men. This underscores the importance of ensuring access to reproductive health rights of women. According to the Nigerian Ministry of Women Affairs and Social Development, $28 \%$ of Nigerian women in their reproductive years have

10 WHO World Health Statistics: Monitoring health for the SDGs 2018 www.bvs.hn (accessed 2020-09-02).

11 UN Goals 5: Achieve gender equality and empower all women and girls https://sdgs.un.org/goals/goal5 (accessed 2021-02-24).

12 UN Goals 5

13 Garcia-Moreno and Amin "The Sustainable Development Goals, Violence and Women and Children's Health" 2006 Bulletin of the World Health Organization 396-397.

14 Guttmacher Institute "Sexual and Reproductive Health and Rights Indicators for the SDGs, Recommendations for inclusion in the sustainable development gaols and the post-2015 development process" 2015 www.guttmacher.org (accessed 2020-08-28).

15 Galati "Onward to 2030: Sexual and Reproductive Health and Rights in the context of the SDG" 2015 Guttmacher Policy Review, https://www.gutt macher.org/gpr/2015/10/onward-2030-sexual-and-reproductive-health-andrights-context-sustainable-development (accessed 2020-08-28).

16 Guttmacher Institute. 
experienced one form of violence or the other since the age of $15 .^{17}$ The SDGs promise is to ensure healthy lives and promote well-being for all at all ages through universal access to sexual and reproductive health care services, including, for family planning, information and education, and the integration of reproductive health into national strategies and programmes. It is of no doubt that SRHR of the female gender that has been relegated in previous years can be reawakened through the active implementation of the SDGs. ${ }^{18}$

\section{Legal framework for reproductive rights in Nigeria}

Nigeria is a pluralistic society and thus laws governing its citizenry are contained in different sources. These are mainly statutory laws, the received English Common law and doctrines of equity, customary law and Sharia law that is applicable mostly in the northern parts of the country. It should be pointed out that some of the laws which make up the legal framework for reproductive rights as discussed in this section are prohibitive in that they are negative rights that do not promote reproductive health rights. However, they are still discussed therein because notwithstanding their contents, they still form part of the laws governing reproductive health rights in Nigeria.

\section{The Nigerian 1999 Constitution (as amended)}

This is the grundnorm from which all other laws in Nigeria derive their validity. The basic question is to enquire if the Nigerian Constitution guarantees a basic right to health for all Nigerians including women. The Constitution does not directly address rights to health, however, there are provisions in it that allude to the right to health. For instance, healthcare provisions are contained in Chapter II of the Constitution which embodies the economic and social policies of the country. Section 17(3) (c) provides that the State shall direct its policy towards ensuring that there are adequate medical and health facilities for all persons. However, the provisions of Chapter II of the Constitution have been excluded from adjudication by the courts, thus, no right of action can ensue from the breach of the provisions of the said chapter by the government. The courts have also held consistently in a plethora of cases that this right as contained in this section of the Constitution is not justiciable. ${ }^{19}$ However, by virtue of judicial interpretations in more recent times, it appears that the non-justiciability of these provisions have been given another

17 Leon "Nigerian Women say No to violence" www.un.org (accessed 202009-01).

18 Nkem and Dimkpa "The Sustainable Development Goals and its promises for the sexual and reproductive health of girls and women in Africa" 2018 Journal of Biosciences and Medicine 105-110.

19 See Okogie v A.G. Lagos State [1981] 2 NCLR 337, Adewole v Jakande [1981] 1 NCLR 262, Ehimare $v$ Governor of Lagos State [1981] 2 NCLR 166. 
outlook, for instance in the case of $A . G$ Ondo $v$ A. G Federation ${ }^{20}$ the court stated that ..... all directive principles need not remain mere or pious declarations. It is for the Executive and the National Assembly, working together to give expression to any one of them through appropriate enactment as occasion demands'. The effect of this landmark decision is that the contents of Chapter II of the Constitution can be subjected to legislative enactment and where this occurs, the courts can enforce the provisions of the law notwithstanding the limitations on non-justiciability contained in Section 6(6) (c). ${ }^{21}$

\section{Violence Against Persons Prohibition Act 2015}

The Violence Against Persons (Prohibition) Act (VAPP) was passed into law in May, 2015. The Act came about as a result of anxieties and activism for protection of persons against the different forms of violence which was becoming a trend in the country. ${ }^{22}$ Thus, the VAPP is an allencompassing legislation covering wide-ranging forms of violence in Nigeria. It regulates violence such as physical violence, psychological violence, socio-economic violence and social violence. It criminalises offences such as spousal rape, spousal battery, and harmful traditional practices such as female genital mutilation. The definition of rape provided in the Act protects both males and females from rape. ${ }^{23}$ The Act categorises domestic offences such as abandonment of children and spouse without any means of sustenance by the man. Under the Act, forceful ejection from marital home by either of the marriage partners is an offence. ${ }^{24}$ A very interesting feature of the Act is that it provides for compensation to victims of crimes under the Act. ${ }^{25}$ The Act authorises protection orders. This order is an official legal document endorsed by a High Court Judge and which restrains a person or persons from further aggressive or abusive conduct towards victims. This provision gives room for victims to apply for protection order to be given in their favour against violators. $^{26}$ The Act also provides for a sexual offender register. ${ }^{27}$ This provision hitherto had been lacking in legislations on crimes and offences in Nigeria. This register is made a public record. As laudable as the provisions of the VAPP Act are, its application is restricted to the Federal Capital Territory, Abuja. Thus, the Act is not applicable in other parts of the country. However, different state legislatures are at liberty to make similar laws with similar provisions. Some states in Nigeria haven taken a cue to do such. For instance, the Oyo State Government passed

20 (2002) NWLR (Pt.772) 222

21 Isokpan "The role of the courts in the justiciability of socio-economic rights in Nigeria: Lessons from India" 2017 Nnamdi Azikwe University Journal of International Law and Jurisprudence, 106-108.

22 Violence Against Persons Prohibition Act (VAPP Act) 2015 Cap A2, Laws of the Federation of Nigeria 2004.

23 S 1(1) VAPP Act.

24 S 9(1) VAPP Act.

$25 \mathrm{~S} 1$ (3) and S 2(5) VAPP Act.

26 S 28-36 and S 46 VAPP Act.

27 S 1(4) VAPP Act. 
Violence against Women Law in 2016. This law protects the female gender specifically from violence in public and private life as well as other harmful traditional practices in the state.

\section{Criminal Code and Penal Code}

The Criminal Code ${ }^{28}$ is applicable in the southern states of Nigeria while the Penal Code operates in the Northern parts. They make provisions for offences relating to reproductive rights. Under the criminal and penal codes, offences are classified based on how grave the offences are into simple offences, misdemeanours and felonies. The offences relating to reproductive rights as contained in the Criminal Code include S214-229, which deals with offences against morality, these offences include unlawful carnal knowledge against the order of nature, gross indecency, unlawful detention in a brothel, attempt to procure a miscarriage or an abortion. Under the Criminal Code, abortion is only allowed where it is done for reasons such as to preserve the life of the mother. ${ }^{29}$

\section{Marriage Act and Matrimonial Causes Act 1973}

The Marriage Act prescribes the age of marriage. This age has relevance to whether a person can possibly attain reproductive rights and health or not. According to the Act in section 18, where either party to an intended marriage is below the age of 21 years, the written consent of either father or mother, or of the guardian where both parents are dead, or are of unsound mind must be produced before the licence is granted or certificate issued. By implication, this law sets the age of consent for marriage at 21 years whilst indirectly allowing persons below the age of 21 to be lawfully married once the parent has given the requisite parental consent. In addition, the Matrimonial Causes Act uses the phrase marriageable age but does not prescribe this age anywhere in the Act. The age of marriage is provided for in respective state legislations, however, there is no uniformity concerning this age.

\section{International Conventions and Treaties}

According to various stipulations of Human RightsConventions and Declarations, countries are mandated to protect SRHR of women while safeguarding their SA, including the enjoyment of violence-free relationships, and protection from relationships and homes filled with violence. Such conventions include:

“1) Convention on the Elimination of all forms of Discrimination Against Women; 30

28 The Criminal Code Act Cap 77, Laws of Federation of Nigeria, 2004.

29 Atsenuwa and Ezeilo 163.

30 Convention on the Elimination of All Forms of Discrimination against Women. Adopted by General Assembly resolution 34/180 of 18 December 1979, entry into force 3 September 1981. 
2) International Covenant on Civil and Political Rights; ${ }^{31}$

3) International Covenant on Economic, Social and Cultural Rights; ${ }^{32}$

4) UN Convention on the Rights of the Child; ${ }^{33}$

5) African Union Protocol on the Rights of Women in Africa; ${ }^{34}$ and

6) African Charter on Human and Peoples' Rights." 35

The rights ancillary to SRHR of women ensured to be protected by State Parties to the Conventions above comprise of:

"i Right to Life: this right offers protection for safe motherhood practices, using FP and safe abortion services to circumvent unplanned pregnancies and pregnancies that threaten a woman's life, thus, limiting the rate of maternal mortality and morbidity. ${ }^{36}$

ii The right to health and medical protection: it ensures the provision of adequate, accessible, cheap, safe, and confidential SRHR care to women during the pandemic. ${ }^{37}$

iii The right to be free from torture and ill treatment: it offers protection against activities that infringes on a woman's SA, including rape, marital rape, forced prostitution." 38

\section{Islamic Law}

It has been said that Islamic jurisprudence is extensively developed in relation to sexual and reproductive rights. ${ }^{39}$ This Islamic approach to protection of women's rights is best shown by reference to the interlinking web of family relationships which evolve round an array of reciprocal rights and obligations. ${ }^{40}$ In the field of reproductive health rights, Islam recognises the right of all persons to marry, the right of all married couples to have children, the equal right of the man and woman to conjugal relations, the right of married persons to plan their family and the right of a married expectant mother to be well maintained by her husband.

31 International Covenant on Civil and Political Rights. Adopted by General Assembly resolution 2200A (XXI) of 16 December 1966, entry into force 23 March 1976.

32 International Covenant on Economic, Social and Cultural Rights. Adopted by General Assembly resolution 2200A (XXI) of 16 December 1966, entry into force 3 January 1976.

33 Convention on the Rights of the Child. Adopted by General Assembly resolution 44/25 of 20 November 1989, entry into force 2 September 1990.

34 Protocol to the African Charter on Human and Peoples' Rights on the Rights of Women in Africa. Endorsed by resolution AHG/Res.240 (XXXI).

35 African (Banjul) Charter on Human and Peoples' Rights. Adopted 27 June 1981, OAU Doc. CAB/LEG/67/3 rev. 5, 21 I.L.M. 58 (1982), entered into force 21 October 1986.

36 Art 6 of ICCPR; Article 6 of CRC; Article 4 of Maputo Protocol; and Article 4 of ACHPR.

37 Art 12 of CEDAW; Article 10 of ICESCR; Article 24 of CRC; Article 14 of Maputo Protocol; and Article 16 of ACHPR.

38 Article 6 of CEDAW; Article 7 of ICCPR; Article 19, 37 and 39 of CRC; Article 4 of Maputo Protocol.

39 Atsenuwa and Ezeilo 163

40 Sada, Adamu and Ahmad "Promoting women's rights through Shariah in Northern Nigeria” 2006 www.ungei.org/files/dfid 1-36 (2020-08-26). 


\section{Materials and methods}

This article adopts a systematic review of grey literature by identifying journal articles, law reports and textbooks on the subject matter. The review was guided by a search using the keywords COVID-19, sexual autonomy, women's rights and reproductive rights. The results of the search was subjected to content analysis. In addition, the research conducted in-depth interviews with women between 15-49 years. This age range depicts the reproductive years of women as seen in the Nigeria Demographic Health Survey 2018. The opinion of the women were used to triangulate documented findings on the subject matter. A total of 45 women were interviewed. The sampling size was limited to 45 because it was observed that the responses had reached saturation point at which time responses being received were getting similar. The women were selected based on their willingness to participate in the discussion and their consent was obtained after the purpose of the research was explained to them and they fully understood. This facilitated discussions between the researchers and the respondents. Four of the respondents were uneducated and the interview was conducted in a native language for them to understand and give responses. The responses were translated back to English language to ensure that the original meaning of the questions were retained. The interviews lasted approximately between 15 to 20 minutes for each respondent. The interviews were carried out over a period of two weeks preceding the total relaxation of most forms of restriction by the Nigerian Government. Furthermore, this research checked online for discussions of Nigerian women on how the pandemic has impacted upon their rights. To this end, Nairaland ${ }^{41}$ forum, a prominent online blog where active discussions take place was understudied to elicit the opinions of Nigerian women on how this pandemic has affected their daily lives. Information from this source was filtered to determine the recurring themes in the discussion about COVID-19 and reproductive rights in Nigeria. This online source was considered necessary due to the sensitive nature of the interview and reluctance of women generally to disclose sensitive issues relating to their personal lives with anyone.

\section{Research instruments}

In-depth Interview guide was the major instrument used in this research. The interview guide was designed and guided by extensive literature review of the subject matter. Open ended questions addressing the topic were used by the researchers for all the women interviewed. In some instances, the researchers asked probing questions to obtain more exhaustive information from the respondents.

41 Nairaland.com https://www.nairaland.com/ (2021-02-24). Nairaland forum is an online community created in 2005. As at January 2018, it had over $1,943,105$ registered accounts and was ranked as the $9^{\text {th }}$ most visited site. 


\section{Data management and analysis}

Data obtained from the in-depth interviews was carefully kept. The data was saved in well protected digital software to ensure confidentiality of the information obtained. Narratives from the interviews was transcribed verbatim. Themes were identified from the discussions in the interviews and subjected to content analysis. For the respondents who were uneducated, the interview was conducted in a native language for them to understand and give responses. The responses were translated back to English language to ensure that the original meanings of the questions was retained.

All ethical considerations were observed in this research and this included seeking the informed consent of the respondents after the nature of the research was explained to them. The respondents were assured of confidentiality and anonymity. No name was required, and each respondent was informed that she could end her participation in the research whenever she no longer wished to continue.

\section{Emergence of Covid-19 pandemic in Nigeria}

On January 31, 2020, the WHO declared an outbreak of COVID-19 as a public health emergency of international concern. ${ }^{42}$ On February 27, 2020, the index case of COVID- 19 was announced in Nigeria. As it was with other countries in the world, the WHO advised on steps to help combat the spread of the disease and protect health systems across the world from collapse. On March 30, 2020, the Federal Government enforced a lockdown order for an initial period of three weeks in some states of the federation which was thereafter extended for a further two weeks. ${ }^{43}$ In addition to this the government placed a strict ban on public gatherings for more than 10 persons. These efforts were supplemented by similar initiatives in several other States, imposing restrictions on entry in and out of the states as well as restrictions on movement within the state, enabling them to buy time for the recommended measures including for testing, isolation and contact tracing to be implemented. ${ }^{44}$

42 A pandemic is a global outbreak of a disease from a new virus that affects the whole country or the entire world. An epidemic refers to an outbreak of disease that occurs over a wide geographic area and affects an exceptionally high proportion of the population and in which the disease is actively spreading.

43 S 1(1) COVID-19 Regulations 2020, Quarantine Act Cap Q2, Laws of Federation of Nigeria 2004.

44 United Nations Development Programme, 'The COVID-19 pandemic in Nigeria: potential impact for the North- East', Available from https// UNDP.NE.covid-19brief (accessed 2020-05-23). 


\section{The Covid-19 pandemic in Nigeria and Reproductive Rights}

As the COVID-19 pandemic deepened, marked by economic and social stress coupled with restricted movement and social isolation measures, gender-based violence increased exponentially. Many women were forced to 'lockdown' at home with their abusers at the same time that services to support survivors were disrupted or made inaccessible. ${ }^{45}$ For instance, the likelihood that women in an abusive relationship and their children were exposed to violence dramatically increased, as family members spent more time in close contact and families coped with additional stress and potential economic or job losses. Women were perceived to have less contact with family and friends who could provide support and protection from violence. ${ }^{46}$ The disruption of livelihoods and ability to earn a living, including for women, decreased access to basic needs and services, increasing stress on families, with the potential to exacerbate conflicts and violence. ${ }^{47}$

Some reports indicate that calls to domestic violence helplines, police and shelters increased during the COVID-19 outbreak. ${ }^{48}$ In other cases, reporting, calls and service use decreased as women found themselves unable to leave the house or access help online or via telephone. ${ }^{49}$ The use of these technologies during confinement and staying at home measures, however, may increase the risk of violence to women and their children as ensuring privacy and guaranteeing confidentiality will be nearly impossible. ${ }^{50}$ Electronic communications can leave a trail. If a perpetrator learns that a woman is sharing her experience it increases her risk of further and even more severe abuse. ${ }^{51}$ Thus, COVID-19 would probably cause a reduction in the provision of SRH services, such as maternal health care and gender-based violence related services; and as attention and resources are being diverted away from SRH provisions,

45 United Nations (UN) "Policy Brief: The Impact of COVID-19 on Women (2020-04) UN Women Headquarters 1-21 https://www.un.org/sexualvio lenceinconflict/wp-content/uploads/2020/06/report/policy-brief-the-impactof-covid-19-on-women/policy-brief-the-impact-of-covid-19-on-women-en1.pdf (accessed 2020-08-26).

46 WHO "COVID-19 and violence against women: What the health sector/ system can do" https://www.who.int/reproductivehealth/publications/emer gencies/COVID-19-VAW-full-text.pdf (accessed 2020-08-26)

47 Gupta "What does coronavirus mean for violence against women?" 2020 Women's Media Centre https://womensmediacenter.com/news-features/ what-does-coronavirus-mean-for-violence-against-women (accessed 202008-26).

48 UN 17-19.

49 Some women use code words at pharmacies to escape domestic violence during COVID-19 lockdown.

50 UN $17-19$

51 National Network to End Domestic Violence (NNEDV) “Technology Safety: Safety Net Project: Using technology to communicate with survivors during a public health crisis" 2020 https://nnedv.org/content/technology-safety/ (accessed 2020-08-26). 
there would be an upsurge in maternal mortality and morbidity, increase in unplanned pregnancies, sexually transmitted infections and diseases (STIs and STDs), HIV, and even death.

\section{COVID-19 pandemic in Nigeria and sexual autonomy: Findings and discussions}

This section presents findings from selected sources on effects of the pandemic. It also presents the opinions of women in their reproductive years on their experiences during the pandemic. For women who had been subject to sexual abuse and loss of sexual autonomy, the COVID-19 pandemic aggravated issues as things got worse during the pandemic. The Mirabel Centre, a one stop centre managed by Partnership for Justice reported that the lockdown led to an increase of over $50 \%$ in the number of reported cases of sexual violence at the centre; and unfortunately, 85 percent of the cases were children. ${ }^{52}$ Similarly, ActionAid Nigeria reported that COVID-19 pandemic exposed a silent culture of violence. As stated by Lola Ayanda, economic fallout led to soaring levels of violence against women and girls. ActionAid documented 299 cases of violence against women and girls between March and June 2020. This report covered 7 states in the federation. 51 of the cases were sexual violence cases that involved minors between the ages of 3 and $16 .^{53}$ In Lagos state, the state run Domestic and Gender Violence Response Team also reported that during the peak of the lockdown in March 2020, the team received on the average 13 new cases of violence daily and in the month of March a whopping 390 cases were received. The Director of the team stated that there was a 60 percent increase in domestic violence, 30 percent increase in sexual violence and 10 percent increase in physical child abuse. ${ }^{54}$

BBC reported about 4 cases of SV occurring within a week in Nigeria. The first was the rape and murder of a 22-year-old university student, named Uwavera Omozuwa, in a church where she was studying in the southern city of Benin. ${ }^{55}$ Others were the rape of a 12 -year-old girl in Jigawa state; the gang-rape and killing of Barakat Bello in Oyo state; and the gang-rape of a 17-year-old girl in Ekiti state. ${ }^{56}$ The Nigerian police recorded 717 rape cases between January and May, 2020. ${ }^{57}$ Presently,

52 UNICEF "COVID-19 children suffer violence during Lagos lockdown" (202007-03) http//www.unicef.org/Nigeria (accessed 2020-08-26).

53 Umukoro "Amidst COVID-19 lockdown, Nigeria sees increased sexual and gender violence" (2020-06-01) Premium Times http//pulitzercentre.org (accessed 2020-08-27).

54 Umukoro "Amidst COVID-19 lockdown, Nigeria sees increased sexual and gender violence" (2020-06-01) Premium Times http//pulitzercentre.org (accessed 2020-08-27).

55 Orjinmo "WeAreTired: Nigerian women speak out over wave of violence" (2020-06-05) BBC News. https://www.bbc.com/news/world-africa-52889965 (accessed 2020-08-27).

56 Orjinmo. 
there is hardly a day when reports of rape or sexual molestation do not make the pages of Nigerian newspapers. ${ }^{58}$

\section{Socio-demographic characteristics of respondents}

A total number of 45 respondents were interviewed. $80 \%$ of them were married. The rest were single but were in one form of relationship or the other. Forty-one $(91 \%)$ of the women were educated having at least Senior Secondary School Leaving Certificate. Four of the respondents were uneducated. The respondents were mainly from the south western part of the country. It is doubtful if the opinions expressed by these respondents will be the same in other geo-political zones of Nigeria. This is due to the diversity of culture and values in the multi-ethnic Nigeria. The findings from the semi structured interviews held with women in this study reflects a variety of opinions on the possible reasons for the reproductive rights violations. These are presented below.

\section{On what sexual autonomy is and how this can be violated}

Reflections from the study carried out by Viswan et $\mathrm{al}^{59}$ shows that sexual autonomy can either be economic autonomy, physical autonomy or decision-making autonomy. The aspect that relates to this present study is decision making autonomy which deals with aspects of sexual relations or reproductive decisions. Respondents were asked what their basic understanding of what sexual autonomy was and how this can be violated.

Out of the 45 participants, 10 of them had never heard of the term sexual autonomy or violence before; 21 had clear understanding and emphasized reproductive rights; while the remaining 14 of them emphasized consent in sexual relations. Majority of the respondents, though educated, had a fair understanding of what sexual autonomy is. However, few other respondents in this study knew nothing about sexual autonomy. For instance, a single female respondent stated categorically:

57 Anon "Nigeria Records 717 Rape Cases in Five Months - Official" (2020-0615) Premium Times https://www.premiumtimesng.com/news/headlines/ 397748-nigeria-records-71 7-rape-cases-in-five-months-official.html (accessed 2020-08-27).

58 Omoniyi "Nigerians call for stiffer punishment as reported rape cases increase" (2020-06-15) Premium Times https://www.premiumtimesng.com/ news/headlines/396497-nigerians-call-for-stiffer-punishment-as-reportedrape-cases-increase.html (accessed 2020-08-27).

59 Viswan et al "Sexual autonomy and contraceptive use among women in Nigeria: findings from the Demographic and Health Survey" 2017 International Journal of Women's Health 538. 
I have never heard about the term sexual autonomy before in my life, I hear about sexual rape on radio but I don't know if it is the same with the autonomy you just mentioned.

\section{IDI/33/22 years}

Findings on the responses of respondents who had a fair understanding of what sexual autonomy is, related sexual autonomy to the ability to make decisions on when to have and with whom to have sexual relations and freedom from coercion in matters of sex. A key factor in determining sexual autonomy for the women was 'consent and the ability to exercise this consent freely and without any form of coercion.' A particular respondent stated that:

For me sexual autonomy is a woman's prerogative to decide who, where and under what circumstances she wants to have sex. For me as a woman, consent is important, and where my consent is inappropriately obtained, through fraud, undue influence, sexual harassment, sexual assault, rape, child defilement, spousal rape, etc, my autonomy as a woman is violated.

\section{IDI/42/30 years}

This differs a bit from what was found in a study carried out in Pakistan in which most of the research findings related sexual autonomy to the ability to control or decide on the number of children one should have and to determine the spacing of the children. All respondents interviewed in this present study agreed that rape constitutes a major way in which a woman's autonomy can be violated.

\section{On knowledge of existing laws and policies that guarantee sexual autonomy for women and freedom from sexual abuse in Nigeria}

A number of studies ${ }^{60}$ have documented the low knowledge and perception of SRHR amongst young women in developing countries such as Nigeria. This was a similar finding in this study. 18 respondents did not know of any existing law or regulation that guarantees sexual autonomy, even though most of the respondents were educated. This can be noted in the following response by one participant:

I don't not know of any law.

\section{IDI/17/31 years}

Out of the 27 participants that knew about the extant laws, 11 had little knowledge about it while 16 of them had full knowledge of the laws.

60 Egenba and Ajuwon "Knowledge and Perception of reproductive rights among female postgraduate students of the University of Ibadan, Nigeria" 2015 African Journal of Biomedical Research 95-105. See also Ogunlayi "An assessment of the awareness of sexual and reproductive rights among adolescents in south western Nigeria" 2005 African Journal of Reproductive Health; Olomola and Ajagunna "Knowledge and Access to Reproductive Health Rights by Adolescents in Ibadan, Nigeria" 2020 African Journal of International and Comparative Law 401-405. 
Respondents who had some legal backgrounds or education were the ones that gave detailed information about the law and its penalty. One participant indicated that:

There are the Criminal Code and Penal Code which prohibit rape (but are inadequate because marital rape isn't recognised).

\section{IDI/4/34 years}

\section{Another respondent submits}

Each state makes its own laws to protect its women. There is a Bill in Oyo State which is at its 2 nd reading which will protect women from sexual abuse. There is presently a contemplation between death by hanging or life imprisonment for its violators. But, I don't know the name of the Bill.

\section{IDI/7/35 years}

I know about Criminal Code prohibiting rape; Lagos State Laws on sexual abuse; Child Right Act protecting children against abuse; and Violence Against Persons (Prohibition) Act of 2016.

\section{IDI/9/30 years}

In another study carried out by Makinde and Adebayo, ${ }^{61}$ knowledge about SRHR as contained in Nigerian statutes was low. In that particular study, respondents could not list any sexual right as found in laws. $10 \%$ of respondents in this study made mention of the Violence against Persons Prohibition Act of 2015 and the Criminal Code of Nigeria whilst others could not mention any laws at all. Some of them could only relate laws on sexual autonomy in Nigeria with laws that imprison offenders for crimes committed.

\section{On experiences in the home and/environment during the COVID-19 Pandemic}

The respondents shared a lot of experiences heard or seen within their neighbourhood during the pandemic, however, only one of the 45 respondents had an unpleasant experience in their home and neighbourhood. 8 of them shared some of the instances of sexual violence perpetuated on fellow women in their neighbourhood; 17 of them either heard on the radio or television while 19 read on social media about sexual violence in Nigeria. For example, a respondent indicated that:

I was almost raped by a drunk man while returning home in the evening from tutorials. Also, men who visit my house (big house) sometimes make attempt to abuse me, but, I normally discourage them by frowning my face.

\section{IDI $/ 2 / 26$ years}

61 Makinde and Adebayo "Knowledge and Perception of sexual reproductive rights among married women in Nigeria" 2020 Sexual and Reproductive Health Matters www.tandfonline.com (accessed 2020-09-07). 
The experiences reported were both positive and negative. Majority of the respondents reported negative effects of the pandemic. For example, a respondent said:

I heard on news and some women in my church complained of sexual abuse especially with the lockdown. Wives being at the receiving end. Also, women with low financial autonomy are mostly victims, for instance, I saw an online video of a woman living in Lagos Island who complained of being sexually abused by her husband from midnight till morning.

\section{IDI /8/34 years}

Another respondent narrated her experience in her neighbourhood, that:

There was a remarked increase in sexual violence, especially among young girls (12-16 years) in the Northern parts who were given out in marriage as Northerners saw the pandemic as a time waster.

\section{IDI/1/32 years}

Majority of respondents' experience either personally or in their environment can be summed up as negative impacts of the lockdown. This corroborates reports on social media about how the pandemic has affected the lives of people. Experiences in other parts of the world on reported effects of the pandemic are not different. For instance, in a study commissioned by the European Parliamentary Forum for Sexual and Reproductive Rights, an overwhelming number of countries in Europe reported substantial increase of cases of sexual and gender-based violence. In the wake of massive lockdowns imposed to contain the spread of the disease, reports of domestic violence surged worldwide. In France, reports of domestic violence increased by $32 \%$. This was attributed to restrictions on movement which forced women and children to be isolated with perpetrators. It also restricted women's escape routes and support networks, such as hotlines and shelters. Economic and social distress further increased loss of sexual autonomy in these countries. Other effects of the pandemic as reported in these countries included significant reduction in access to essential SRHR services such as lack of respectful maternity as care during maternity became compromised. Birth companions were not allowed and newborn babies were separated from their mothers at birth. In addition, immediate risks of unintended pregnancy increased as women had to wait to access scheduled contraceptive injections. In countries where telemedicine was not accessible, women abstained from physical visits to the hospital. Some countries reported shortage in contraceptives due to restrictions on exportation of products containing progesterone. ${ }^{62}$

62 European Parliamentary Forum for Sexual and Reproductive Rights and International Planned Parenthood Federation "Sexual and Reproductive Health and Rights during the COVID-19 pandemic" www.ippfen.org (accessed 2020-09-10). 
Contrary to reports on media on the effects of the pandemic which were mostly negative and untoward, a few respondents reported positive impact of the pandemic. A particular respondent affirmed as such:

I have had a good experience during this pandemic. Although some bad news were reported, for me, it has impacted on my sexual relationship with my husband positively. There was more time for bonding during the lockdown as my husband doesn't work in the city where my children and I live.

IDI/18/31 years

\section{On how COVID-19 pandemic has personally impacted upon sexual autonomy and sexual violence?}

One out of the 45 interviewed respondents admitted that they had a personal sexual violence encounter during the pandemic, probably because some felt that such issues were too personal and did not wish to disclose this. For this aspect, the researchers have relied extensively on reports from social blogs where people relay their experiences with others to add to what the interviews reported.

On Nairaland, a particular respondent affirmed that she was sexually abused by her step-father during the lockdown. She claimed that her step-father who worked in a biscuit factory was laid off work during that time and this made the step-father stay at home with her during the lockdown. 63

When asked questions relating to personal impact of the pandemic, the respondents had differing encounters; some believed the pandemic had a positive impact because movement of proposed sexual offenders' was restricted and as such they could not go about to perpetrate their nefarious activities. Another respondent had this to say:

It has impacted on sexual autonomy negatively, and also increased its prevalence. It has made women more vulnerable. Some women lost their jobs. Men are more cranky and aggressive, and resort to abuse their wives. However, COVID-19 has helped to create more awareness about sexual violence. My neighbour now goes to Lagos markets to enlighten women about their sexual autonomy and contraception.

IDI/29/ 34 years

Another female commented on her experience thus:

Negatively-because men with high libido raped their wives, and positively-it increased sexual relationships among couples as they were able to have more consensual sex during the lockdown.

\section{IDI/9/30 years}

Other respondents lamented that a number of non-governmental organisations focusing on women and children's rights had to be closed

63 Nairaland.com https://www.nairaland.com/ (2021-02-24). 
down due to the lockdown restrictions and this made help inaccessible to vulnerable women. Another positive impact of the pandemic as reported by a particular respondent was that the pandemic gave women voices to be heard on sexual abuse, especially through social media like Twitter.

\section{On the steps that can be taken by the Nigerian Government, with a view to the SDG timelines, in protecting women's reproductive rights during the COVID-19 pandemic?}

Countries that aim to achieve SDGs must realise that SRHR of the populace must be met at all times. Respondents in this study gave their opinion on how best to ensure that SRHR of women are saved from jeopardy given that the timelines for the achievement of the sustainable goals are just around the corner. They all had different opinions ranging from recommendations for stiffer sanctions and penalties for sexual offenders. Some respondents believed that the Nigerian culture has contributed to the manner in which women are treated. Majority of the responses of the women in this section focused on the victims. To them, in most instances of infringement of sexual autonomy, less attention is paid to the victim while most attention is placed on the crime committed and the perpetrator of the crime. To the women, attention can be given to the victim through establishment of victim support network that aid in the recovery and healing of victims and in addition, provision of adequate counselling to victims of abuse. Some said the criminal justice system should be improved to fast-track cases relating to sexual abuse. Others recommended enlightenment and more awareness on sexual autonomy and the rights of women in particular. A particular respondent stated:

We can only speak of guarantee for the rights of women when every woman everywhere is made aware of their rights, we need more information on our rights as women. Our culture has encouraged silence as the role of women in the society, this ought not to be. Let us teach our children from infancy that a girl has rights to be respected and when these rights are not respected, there should be some form of legal redress.

\section{IDI/40/24years}

\section{Conclusion}

Previously stated, SRHR is vital to the attainment of the right to the highest standard of physical and mental health of women. Similarly, it is important for a woman to be able to exercise her sexual autonomy in determining when, with whom, and under what circumstances she wishes to engage in sexual activity. However, where a woman is disrobed of this right, sexual violence occurs. Although, sexual violence is an unfortunate incident for any woman, its prevalence increased not only in Nigeria, but also worldwide with COVID-19 pandemic. 
According to the World Bank, ${ }^{64}$ experiences from previous pandemics have shown that women and girls can be active actors for change because they can experience effects of crisis in different, but mostly negative ways. This study has presented the impacts, albeit mostly negative, the COVID-19 pandemic has had on sexual autonomy and sexual violence in Nigeria. The study has also shown that the COVID-19 pandemic can possibly create a setback in realising these targets. Maintaining the momentum towards actualisation of SRHR as contained in the SDGs is only possible if countries have the political will and the capacity to prioritise regular, timely and reliable data collection to guide policy decisions and public health interventions. The current administration in Nigeria kicked off with a roadmap to ensuring the actualisation of the SDGs. This roadmap can only be adhered to where there is a political will to overcome all obstacles in the implementation of SRHR. Political will is expressed in adequate funding and active implementation of the existing legal framework thus making SRHR priorities for action.

64 Paz et al "Policy Note: Gender dimensions of the COVID-19 pandemic" (2020-04-16) World Bank Group 1-19 www.openknowledge.worldbank.org (accessed 2020-09-11). 